To link to this article / Para enlazar con este artículo:

https://doi.org/10.14198/fem.2020.35.09

To cite this article / Para citar este artículo:

Garrido Carrasco, Vicenta. «Los arquetipos masculinos de los cuentos de Perrault: modelos de masculinidad que aprender o desaprender desde la infancia». En Feminismo/s, 35 (junio 2020): 235-262.

\title{
LOS ARQUETIPOS MASCULINOS DE LOS CUENTOS DE PERRAULT: MODELOS DE MASCULINIDAD QUE APRENDER O DESAPRENDER DESDE LA INFANCIA
}

\author{
THE MALE ARCHETYPES IN PERRAULT'S TALES: \\ MODELS OF MASCULINITY TO LEARN OR UNLEARN \\ FROM CHILDHOOD
}

\author{
Vicenta GARRIDO CARRASCO \\ Universidad de Jaén, Jaén \\ garrido@ujaen.es \\ orcid.org/0000-0001-6491-4483
}

\section{Resumen}

Charles Perrault escribe sus cuentos dentro del preciosismo, movimiento de reivindicación femenina que nace y se desarrolla en los salones de París en la segunda mitad del siglo XVII. Las preciosas, que primero cuentan y después escriben cuentos de hadas en los salones, harán que el cuento se consolide como género literario y pase de la forma oral a la escrita. El interés que en los últimos años ha suscitado el estudio de la masculinidad en numerosas disciplinas científicas, refleja la necesidad social de que se instaure en la realidad cotidiana de hombres y mujeres una nueva masculinidad. El análisis de lo masculino en los cuentos de Perrault, de todos conocidos, pone de manifiesto que estos contribuyen a la formación de una identidad de género masculina la cual no se corresponde con las necesidades de nuestra realidad actual. Se impone la deconstrucción del concepto de masculinidad que presentan tales cuentos para implantar, desde la infancia, nuevas masculinidades. 
Palabras clave: masculinidad; arquetipos; identidad de género; cuentos de hadas; Perrault.

\begin{abstract}
Charles Perrault writes his tales within the preciosity, a movement of female assertion born and developed in Parisian salons during the second half of the 17th century. Précieuses, who first tell and then write fairy tales in salons, will consolidate fairy tales as a literary genre as well as their transition from the oral to the written form. The interest elicited by the study of masculinity in many scientific disciplines in recent years reflects the social need that a new masculinity be established in the everyday reality of men and women. An analysis of the masculine in the tales by Perrault, known to all, reveals that they contribute to creating a male gender identity that does not match the needs of our current reality. Deconstructing the concept of masculinity presented by such tales becomes thus essential in order to establish new masculinities since childhood.
\end{abstract}

Keywords: Masculinity; Archetypes; Gender identity; Fairy tales; Perrault.

\title{
1. INTRODUCCIÓN
}

La masculinidad en el mundo actual es objeto de estudio y de interés social debido a las transformaciones de los roles de género de hombres y mujeres. Poner de manifiesto lo que significa la masculinidad es algo complejo porque supone relacionarla con los conceptos que sobre lo masculino tiene una sociedad y los diferentes grupos que la integran en una cultura determinada. En su significado aparecerán conectados multitud de aspectos -época histórica, edad, clase social o cultura-, que pueden ser diferentes de un grupo a otro, de una sociedad a otra y de una cultura a otra (Jociles Rubio 2).

Lo masculino y lo femenino están unidos al sexo y al género. El sexo alude a las diferencias biológicas entre hombres y mujeres, mientras que el género se refiere a la construcción cultural y social del sexo que cada sociedad tiene de lo femenino y de lo masculino (Sau y Jayme 60-65), que, desde la infancia, se adquiere a través del aprendizaje y de la socialización.

Cuando Simone de Beauvoir dice «no se nace mujer, se llega a serlo» (Beauvoir 13), habla de género. Esta afirmación podría utilizarse refiriéndose 
a los hombres diciendo que «no se nace hombre, se llega a serlo». Para Connell la masculinidad «es al mismo tiempo la posición en las relaciones de género, las prácticas por las cuales los hombres y las mujeres se comprometen con esa posición de género y los efectos de estas prácticas en la experiencia corporal, en la personalidad y en la cultura» (35). Connell (31-48) o Bonino Méndez (7-35) definen como «masculinidad hegemónica» la que otorga mayor valoración a lo masculino que a lo femenino, asocia a los hombres comportamientos como la competitividad, la demostración de virilidad, la búsqueda del riesgo, la heterosexualidad o el uso de la violencia (parámetros que interactúan con la raza y con la clase) y legitima el poder masculino a través de las organizaciones sociales y la cultura. Ellos serán activos, fuertes, jefes del hogar y proveedores de la familia, responsables y autónomos y no deberán expresar sus emociones ni demostrar miedo.

Hemos escogido los cuentos de Perrault para analizar la masculinidad que transmiten por dos razones: primero, porque han sido traducidos al español y forman parte de nuestro acervo cultural; y, segundo, porque lo que narran estos cuentos tendrá importantes consecuencias cuando se reproduzcan, desde la infancia, los arquetipos masculinos que contienen. Nuestro objetivo es revisar el modelo de masculinidad que presentan, que ha generado, a su vez, un modelo de feminidad determinado, para constatar si se corresponden con las necesidades del mundo actual.

\section{EL CONTEXTO SOCIAL Y CULTURAL EN EL QUE PERRAULT ESCRIBE SUS CUENTOS}

Charles Perrault (1628-1703) vive y desarrolla su obra literaria en la corte Luis XIV, el «Rey Sol», donde llega a ser Inspector General de Obras del Rey, cargo que le otorga un despacho en Versalles. La vida en la corte influirá y se reflejará en las cuarenta y seis obras que escribe el autor, que alcanzará la fama por sus cuentos. Participa de la Querella entre Antiguos y Modernos tomando partido por los últimos (Soriano 267-294, 295-307). Escribe dos tipos de cuentos diferentes en cuanto a forma y estilo: por un lado, tenemos tres cuentos en verso en los que utiliza una retórica afectada ( «La marquesa de Saluses o La paciencia de Grisélidis» (1691), «Los deseos ridículos» 
(1693) y «Piel de asno» (1694)); y, por otro, ocho cuentos en prosa ( $« \mathrm{La}$ bella durmiente», «Caperucita roja», «Barba azul», «El gato con botas», «Las hadas», «Cenicienta» y «Riquete el del copete»), donde se aborda el problema de la autoría entre Perrault y su hijo Pierre (Henriot 424-441). La colección completa se publica en 1697 bajo el título Historias o Cuentos de antaño. La crítica literaria ha puesto de manifiesto las diferencias entre los cuentos escritos en verso y en prosa, destacando la calidad de los segundos sobre los primeros. Soriano, gran conocedor de Perrault y su obra, manifiesta sobre este tema:

La participación de Perrault en ellos no fue ocasional, ya que forman un conjunto que posee una unidad y una estructura sólida y uniforme, y si no fue su autor pudo reescribirlos dándoles su sello característico, aunque ninguna de las ediciones, que aparecen en vida de Perrault, lleven su nombre, y la dedicatoria y el permiso de imprimir aparezcan a nombre del tercer hijo del académico. (Soriano 74)

Charles Perrault es uno de los pocos autores de la época que participa en el movimiento de reivindicación femenina del preciosismo (1650-1703). Los salones franceses, donde este nace y se desarrolla, se constituyen como ámbitos de socialización y de aprendizaje femenino (Garrido Carrasco 54-59). Destacó por su gran influencia, entre otros, el salón de la marquesa de Rambouillet, que tuvo la habilidad, por un lado, de mezclar en él los dos sexos como iguales, convirtiéndolo en un espacio pedagógico para que hombres y mujeres conversaran de temas intelectuales y científicos, animando sin descanso a sus amistades femeninas a cultivarse para poder estar a la altura en todas las discusiones, y, por otro lado, reunir a los artistas que destacaban en el momento con los miembros de la aristocracia (Anderson y Zinsser 126). Y lo que comenzó como un agradable pasatiempo para las clases nobles se constituyó en una institución social, donde hombres y mujeres aprendieron nuevas formas de pensar y comunicarse y nuevos patrones de comportamiento.

La mujer preciosa sigue una rígida disciplina y actúa siguiendo los dictados de la razón, enseñando a los hombres a dominar las pasiones y los sentimientos que podían provocar desorden en el ánimo, favoreciendo un equilibrio de pensamiento donde prevalecía el sentimiento de la ternura y la 
dulzura, según se recoge en La Carte de Tendre, representación topográfica y alegórica de la conducta y la práctica amorosa que moldeaba las relaciones galantes incluida en el primer volumen de la novela Clélie (1654) de Mlle de Scudéry (Garrido Carrasco 57, 77). El amor, convertido en la preocupación por excelencia, y la mujer, en objeto de conquista y no de placer, solo podían conseguirse por medio del ritual de la galantería (Denis 179-189).

Como consecuencia de este cambio de posición de las mujeres que reclamaban igualdad, respeto y buen trato, se fragua, dentro del preciosismo y en el ámbito del salón, el nuevo ideal de honnête homme: hombre de bien o cortés (Dens 69-82), cultivado, moderado, con sentido de las conveniencias sociales y que gusta de la vida mundana de la época. Poseía sentimientos nobles, agrado, urbanidad y amenidad en la conversación, como recoge Faret en su tratado L'honnête homme ou L'art de plaire à la cour (1630), inspirado en El Cortesano de Castiglione.

La obra Astreé (primera novela-río de la literatura francesa 1607-1627) de Honoré d'Urfé tuvo gran influencia en las preciosas y en el ambiente del salón y contribuyó a separar el amor de la sensualidad vulgar y de la pasión ciega, transmitiendo el mensaje del neoplatonismo que ponía el amor por encima de todo, pero no el amor concupiscente sino el que refleja la belleza ideal a la que aspira el alma.

El rechazo de los matrimonios acordados y la defensa de la libre elección fue un punto clave de las reivindicaciones de las preciosas. El amor y el matrimonio ocupaban el centro del debate; marido y amante eran dos conceptos disociados en la época: «marido» significaba sometimiento social y sexual y «amante», amar y ser amada (Mongrédien 149-150). Las preciosas negaban lo carnal en el amor, por lo que se las llamó «gazmoñas» o «puritanas», mojigatería que critica Molière en Las Preciosas ridículas. Saint-Évremond y Ninon de Lenclos las denominaron «jansenistas del amor» (Soriano 260) debido a lo estricto de este movimiento religioso que influyó en la época y del que Perrault participa por la educación inculcada por su padre. Esta austeridad se acompañaba de coquetería y del amor galante y cortés en el que se podían saborear, en toda su amplitud, los matices del sentimiento. Mme de La Fayette, en su frase « ¡Adiós al amor que no perdura tras la posesión!» (Dulong 446), lo pone de manifiesto. Asidua del salón de la marquesa de 
Rambouillet, publicó, al principio de forma anónima, su novela La Princesse de Clèves, donde expone su idea del amor que defiende la virtud por encima de la pasión.

Otras preciosas utilizaban su propia sexualidad en vez de negarla, por lo que se dudaba de su autenticidad como tales: eran las salonières (Anderson y Zinsser 127). En el salón podían obtener mayores beneficios estableciendo, más que rechazando, una relación sexual con un hombre de título o talento. A finales del siglo XVII y durante el XVIII estas salonières eran famosas por sus asuntos amorosos y sus matrimonios con hombres importantes. Como ejemplo tenemos el salón de Ninon de Lenclos (1620-1705), famosa cortesana de la época. Si una salonière mantenía la castidad era criticada sin piedad. La creencia era que las relaciones entre los sexos, por muy intelectuales o artísticas que pudieran parecer, no podían permanecer platónicas.

Resumiendo, podemos decir que:

El preciosismo, heredero del feminismo francés que arranca de la Edad Media (las cortes de amor) y del Renacimiento (con Christine de Pisan, Louise Labé y otras famosas literatas) es, ante todo, uno de los primeros movimientos feministas de Occidente. Se construye sobre dos axiomas: la igualdad entre hombre y mujer en el amor, con el derecho de las mujeres a elegir su pareja en igualdad y la aportación del hombre a esta de un conjunto de cualidades capaces de convertir el amor no solo en una realización física, sino también en una realización intelectual, imaginativa y estética. El segundo axioma defiende el derecho de las mujeres a acceder a los bienes del espíritu, compartiéndolos, o no, con su condición de esposas y madres sin recibir a cambio ningún menosprecio. (Prado Biezma 123-147)

Para Soriano, Perrault «se mueve en su obra entre un preciosismo y antipreciosismo constante» (255-266) y sus cuentos no son una excepción. Con ellos obtuvo un gran éxito, aunque la verdadera creadora del género de los «cuentos de hadas» fue Madame d'Aulnoy cuando publicó «La Isla de la Felicidad»-primer cuento de hadas literario francés- dentro de la novela Historia de Hipólito, conde de Duglas en 1690 (Defrance 145-152). La expresión «la moda de los cuentos de hadas» aparece en la dedicatoria de Finette de Mademoiselle L'Héritier, sobrina de Perrault, cuando escribe: «c'est la mode: vous les aimez [les contes]: je m'accommode à l'usage avec plaisir» (LHéritier 230). Esta moda, que se relaciona con la cantidad, con 
el apasionamiento por el tema y con la concentración del fenómeno en un periodo concreto -segunda mitad del siglo XVII y el primer cuarto del siglo XVIII en Francia- llevó a la crítica a hablar de «la moda de los cuentos de hadas» (Yllera Fernández 421-422).

Los destinatarios de estos cuentos eran los adultos: preciosas y preciosos que se reunían en los salones de París y exploraban nuevas formas de pensamiento y de comunicación por medio de la conversación y la palabra con el objetivo de que las mujeres pudieran conseguir nuevas posibilidades de ser y de realizarse. Entre otras actividades competían contando cuentos, llegando a tal perfección que comenzaron a escribirlos. De esta forma, el cuento alcanza la categoría de género literario con carácter femenino y precioso (Garrido Carrasco 89-90). Las preciosas expresan en sus cuentos sus reivindicaciones y eligen al hada -figura femenina de poder- como su valedora, demostrando que pueden escribir y publicar como los hombres.

Aunque al principio los destinatarios de sus cuentos eran los adultos, Perrault comienza a presentarlos como narraciones para niños ${ }^{1}$ por las enseñanzas que recogían las moralejas que colocaba al final de cada cuento. A partir del didactismo del siglo XVIII comienzan a considerarse un género adecuado para facilitar el aprendizaje y contribuir a la educación en la infancia. Generalmente los contaban madres, abuelas, ayas o niñeras, como se recoge en la moraleja de «Piel de asno», lo que podría llevar a pensar que a las mujeres se les otorgaba el papel de guardianas y transmisoras de los valores que se recogen en ellos. Cuentos como «Cenicienta», "Caperucita» o «La bella durmiente», contados y leídos de generación en generación, han influido en la construcción de la identidad de género de los hombres y de las mujeres; de ahí nuestro interés por descubrir su modelo de masculinidad.

\section{LOS PERSONAJES MASCULINOS DE LOS CUENTOS DE PERRAULT}

Para descubrir cómo se manifiesta la masculinidad en los cuentos de Perrault, analizaremos el discurso de los textos y las diferentes informaciones que conforman los arquetipos de masculinidad que contienen. Revisar también

1. En este artículo el masculino genérico siempre engloba ambos sexos.

Feminismo/s 35, junio 2020, pp. 235-262 
las imágenes que apoyan los textos contribuirá a enriquecer y completar nuestro análisis. Hemos tomado como criterio para el análisis la importancia del personaje masculino dentro de cada cuento.

Debemos relacionarlos con el contexto del autor, expuesto brevemente en el apartado anterior, y con lo que narra cada cuento sobre la masculinidad en su contexto social, político y cultural porque «las convenciones sociales del contexto recogen un conjunto de sucesos que presentan un estado inicial, un estado intermedio y un estado final» (Van Dijk 273-274) que podrían corresponderse con el planteamiento, nudo y desenlace del cuento. Investigar desde una óptica feminista cómo aparece la masculinidad en los cuentos de Perrault va a permitir constatar si la construcción social de género que contienen es la propia del patriarcado, donde son los hombres quienes ejercen la jerarquía, el estatus y el poder sobre las mujeres. Como apunta Bourdieu, «El orden social funciona como una inmensa maquinaria simbólica que tiende a ratificar la dominación masculina en la que se apoya. [...] El análisis científico de una forma de dominación tiene efectos sociales [...] y puede contribuir a neutralizarlo» $(22,137)$.

Por tanto, a la hora de llevar a cabo el análisis de la masculinidad en los cuentos de Perrault, no podemos perder de vista que fueron recopilados y escritos en un momento histórico determinado, que incluían la ideología del patriarcado y las condiciones sociales, económicas y culturales del mundo occidental, en el que el cristianismo ha tenido una influencia trascendental, y que, además, arrastraban un sustrato cultural e ideológico ancestral. Por otra parte, tampoco podemos obviar que los modelos y contenidos de esos cuentos, que se aprenden y se reproducen desde la infancia, generarán relaciones de poder, como indica Fairclough (179-201), en un mundo que ya no es el mismo, pero donde se ofrecen siempre los mismos modelos de masculinidad y las mismas alternativas de lo que significa ser hombre.

Tomando como corpus para nuestro análisis los Cuentos de antaño $o^{2} \mathrm{de}$ Perrault, exponemos en la siguiente tabla el título de cada cuento, los personajes masculinos que aparecen en cada uno de ellos y la función que realizan.

2. La edición utilizada es la que figura en el apartado final de «Referencias bibliográficas».

Feminismo/s 35, junio 2020, pp. 235-262 
Los arquetipos masculinos de los cuentos de Perrault: modelos de masculinidad que aprender o desaprender desde la infancia

\begin{tabular}{|c|l|}
\hline \multicolumn{3}{|c|}{ Personajes masculinos en los cuentos de Perrault } \\
\hline \multicolumn{2}{|c|}{ Cuentos en prosa } \\
\hline Cuento & Personaje/es masculinos:Función \\
\hline $\begin{array}{c}\text { "La bella durmiente" } \\
\text { (BD) }\end{array}$ & - El rey, padre de La belladurmiente \\
- El príncipe que busca una esposa bellay durmiente
\end{tabular}

Feminismo/s 35, junio 2020, pp. 235-262 
Lo primero que llama la atención observando la tabla es que reyes, príncipes y señores nobles son los personajes masculinos que aparecen en casi todos los cuentos de Perrault; las clases sociales más bajas están menos representadas. También merecen destacarse las actuaciones del ogro -personaje masculino mitológico-y las de los animales que desarrollan papeles masculinos.

En los siguientes apartados vamos a exponer los aspectos más significativos que sobre la masculinidad hemos recogido en nuestro análisis, reproduciendo de forma escueta los fragmentos del texto que corroboran lo que relata cada cuento. Para evitar redundancias, siempre que citemos un cuento haremos referencia a su título con las iniciales que aparecen debajo de su nombre en la tabla anterior, seguidas de la página correspondiente.

\section{LOS REYES COMO ARQUETIPO MASCULINO DE PODER QUE SOSTIENE EL PATRIARCADO}

El personaje masculino del rey que aparece en los cuentos de Perrault ofrece escasas descripciones físicas y psicológicas. Aunque encarna el máximo poder en la escala social como rey y como hombre, nunca aparece como protagonista ni da título a ningún cuento. Su ámbito de acción es externo. Uno de los cuentos en los que se manifiesta el poder del rey de forma más absoluta es «Piel de asno», en el que el rey es tan "amable en la paz como terrible en la guerra» (PA 233). Las grandes posesiones que respaldan su poder se detallan en el cuento. La más preciada era un asno que, «en lugar de boñigas, cada mañana, soltaba buenos Luises y Escudos» (PA 234). Otro ejemplo lo encontramos en «La bella durmiente»: «El rey mandó que le dieran un cubierto [de oro y piedras preciosas al hada]» (BD 11).

Sin embargo, a pesar de ostentar el máximo poder, el rey pide ayuda a las hadas para tener descendencia, escucha sus consejos y se muestra galante siguiendo las reivindicaciones de las preciosas de la época, que reclaman buenos modales y galantería para las mujeres: «El rey le ofrece la mano [al hada], cuando bajaba de la carroza» (BD 15). Acepta sus predicciones y las tiene muy en cuenta -como vemos en «La bella durmiente»-cuando ordena publicar un edicto bajo pena de muerte para impedir que la princesa se pinche el dedo y duerma cien años (BD 13). 
El matrimonio y la paternidad son dos aspectos íntimamente relacionados con el personaje del rey que revelan muchos aspectos sobre la masculinidad.

\subsection{Reyes y matrimonio}

El amor y las riquezas son los motivos que llevan a los reyes a contraer matrimonio en los cuentos de Perrault. El autor introduce el amor como sentimiento de pareja de una forma sutil siguiendo las reivindicaciones de las preciosas. Así lo encontramos en «Piel de asno», donde se refiere que el matrimonio del rey era dichoso por las cualidades de su esposa: «fiel, bella, encantadora, de carácter dulce, delicado, y acomodado» (PA 233), entendido como «fácil de contentar» (RAE 33). Otra razón de peso para casarse son las riquezas que pueda aportar al matrimonio la elegida. En «La bella durmiente» «[el rey] la temía [a la reina] porque era de raza de ogros, y se había casado con ella por sus muchas riquezas» (BD 25).

En estos matrimonios el sexo no se manifiesta de forma explícita, sino que aparece como necesario para tener descendencia. «Piel de asno» define el matrimonio del rey como casto: «De casto himeneo» (PA 233). En la definición de incesto que aparece en el DRAE encontramos que este término viene del latín incestus («incasto», «no casto»): «Relación carnal entre parientes dentro de los grados en que está prohibido el matrimonio» (DRAE 1260). Por tanto, este matrimonio se entiende como «casto» porque entre los cónyuges -el rey y la reina- no existe consanguinidad. Fruto de este casto matrimonio nacerá una hija tan excepcional como la madre. Tras morir esta, en la trama del cuento se presenta el deseo incestuoso del padre, el rey, hacia su hija, la princesa.

Aunque en algunos cuentos los reyes se manifiestan apenados por la muerte de sus esposas, pronto piensan en volver a contraer matrimonio. «Piel de asno» es un buen ejemplo: el rey, ante la muerte próxima de su esposa, le promete que no se casará más, pero ella le hace jurar que solo se casará de nuevo si encuentra una mujer «más bella y mejor hecha que yo, buena y prudente» (PA 235). Al enviudar, el rey manifiesta un gran duelo que le dura poco y se pone a buscar esposa, pero no encuentra ninguna que iguale a la reina muerta. Solo la supera su hija, y el rey -su padre- quiere casarse con ella. 


\subsection{Reyes y paternidad}

Los reyes de los cuentos de Perrault aparecen preocupados por tener descendientes a quienes dejar su reino y sus bienes. Así, en «La bella durmiente» encontramos al rey afligido, junto a la reina, por no tener hijos. Cuando consigue tener una princesita, invita a las hadas para celebrar el bautizo: «todos los invitados volvieron al palacio del rey» (BD 11), pero ahora no se alude a la reina, madre de la princesa, tal vez porque ya ha cumplido con su función procreadora.

En los cuentos de Perrault el derecho de primogenitura se impone de forma desigual entre hombres y mujeres, tanto en la realeza como en las clases bajas. Si la primogénita es una mujer, esta no podrá hacerse cargo de los bienes ni de los derechos que legítimamente le corresponden. Aunque sea princesa, no reinará cuando herede la corona, sino que necesitará un príncipe que se case con ella para reinar y su función será, exclusivamente, la de esposa y madre. El rey de «El gato con botas» ostenta el poder de su reino, pero consiente en casar a la princesa, su heredera, con el hijo del molinero para dar continuidad a su estirpe, creyendo que este -gracias a la astucia de su gato- es el marqués del Carabás, que posee un castillo y muchas tierras (Propp 493-495).

Llama la atención el incesto que se plantea en «Piel de asno» entre el rey y su hija, justificándose en el cuento porque «[...] era más bella / y un juvenil encanto poseía / que la difunta [su madre, la reina] al fin ya no tenía» (PA 236). Para reforzar su posición de poder y justificar su deseo incestuoso, el rey recurre a un «casuista» que, «resolviendo el caso a simple vista / juzgó posible tal proposición» (PA 236). La figura del casuista se entiende como «un experto en teología moral, especializado en casos de conciencia o conducta a seguir» (Perrault 287). Según el texto, todos los deseos del rey se satisfacen aunque no sean correctos, moral o socialmente, pero además son validados por un «experto», otra figura masculina, que otorga al deseo real legalidad, moralidad y refrendo social.

Solo la figura femenina del hada madrina, que atiende las razones de la negativa de la princesa, se atreve a contrariar el deseo real: «Sería un gran pecado / acceder a las locas pretensiones, / mas sin contradecirle, con mis trazas, / hay un modo de darle calabazas» (PA 239). Para conseguir su objetivo 
el rey accede a todas las peticiones de la princesa, incluso a regalarle la piel de su preciado asno; piel con la que, disfrazada, ella escapará. Ante la realidad de su fuga, el rey enviará a sus criados a buscarla, pero no la encontrarán. Al final del cuento, el padre de Piel de asno, que había superado su pasión por ella, asiste a su boda. Para Bettelheim «el deseo incestuoso se resuelve desplazando el vínculo amoroso desde el padre hacia el amante» (206) o el enamorado. Para ello la protagonista debe pasar por una serie de experiencias que la conducirán hacia su madurez psicológica.

\section{LOS PRÍNCIPES: HEREDEROS Y CONTINUADORES DEL SISTEMA}

Aunque en los cuentos de Perrault la figura del príncipe aparece como protagonista junto a otro personaje femenino, ninguno da título a sus cuentos -excepto Riquete-, dejando esta prerrogativa a La bella durmiente, Cenicienta, Caperucita, Piel de asno o Grisélidis. Ellas cobran importancia en el planteamiento y desarrollo de la acción narrativa, convirtiéndose, en la mayoría de los casos, en las verdaderas protagonistas. Los príncipes aparecen gobernando su reino a la muerte de sus padres y realizando actividades que recuerdan a las de los nobles de Versalles: cazan, bailan o disfrutan del carnaval o del teatro, todo en un ámbito de acción externo. Y para asegurar la continuidad de su dinastía y del reino buscan una esposa bella que posea unas cualidades adecuadas.

En Perrault encontramos príncipes apuestos, como el de «Piel de asno»: «bello, de noble porte y aspecto marcial» (PA 247), o grotescos, como Riquete: «feo, muy desagradable pero magníficamente vestido, [...] cortés y respetuoso» (RC 123). El príncipe de «Grisélidis» era «valiente, hábil, vigoroso, guerrero, impetuoso, y ama las Bellas artes. [...] Le gustaba el combate, la victoria, / [...] hacer al pueblo suyo venturoso. [...] Pero un humor sombrío oscurecía / este temperamento valeroso / que triste y melancólico le hacía / ver en su pecho siempre receloso, / al bello sexo infiel y mentiroso» (G 181182). Estas características de masculinidad se corresponden con el canon que imperaba en las cortes medievales y en la propia época del autor. Vamos a repasar a continuación tres aspectos que aportan mucha información sobre el concepto de masculinidad que transmiten los príncipes de los cuentos de Perrault. 


\subsection{Los príncipes como enamorados}

Una de las reivindicaciones de las preciosas es conseguir un matrimonio por amor. Los príncipes de los cuentos de Perrault siguen, en líneas generales, las normas sociales que responden al trato galante que impera en el salón del preciosismo: «La bella durmiente» recoge que «El príncipe ayudó a la princesa a levantarse [...] pero él se guardó de decirle que iba vestida como su abuela» (BD 24). Es galante pero miente para conseguir sus objetivos. Si ejercen el poder como príncipes, la galantería del preciosismo no se impone. Así lo podemos constatar en «Cenicienta» cuando, tras la prueba del zapato, el príncipe no va a recogerla y envía un lacayo: «La llevaron al príncipe, ataviada como estaba y la encontró más bella que nunca» (C 110). Por tanto, él no se comporta como enamorado sino como príncipe y no la considera su igual.

Ellos tienen la prerrogativa de elegir pareja y ellas deben esperar a ser elegidas: en «La bella durmiente», «La princesa cae en un profundo sueño que durará cien años al cabo de los cuales [...] la despierta el hijo de un rey, a quien estaba destinada» (BD 13, 19). Este príncipe quiere una esposa bella y durmiente, que acepte todas sus iniciativas y que lo espere eternamente. Características propias del patriarcado que las quiere «bellas» $\mathrm{y}$ «durmientes», como dice Fernández Rodríguez (64-66). Así lo vemos en «Cenicienta», «Las hadas», «El gato con botas», «Grisélidis», «Piel de asno» o «Riquete el del copete».

La pasión que experimentan estos príncipes no aparece explícita en los cuentos. La excepción es «La bella durmiente», donde encontramos que el príncipe la besa y, después de haber celebrado la boda, «El joven príncipe se sintió arder de pasión [...]. Creyó sin vacilar que él llevaría a cabo tan bella aventura, empujado por el amor y la gloria. [...] un príncipe joven y enamorado siempre es valiente» (BD 19, 21). El texto revela que para él este matrimonio es un lance, una conquista. En el mismo cuento también encontramos demostraciones de amor: «le aseguró que la quería más que a sí mismo» (BD 23). Pero, aunque la quería más que a sí mismo, tras la boda «la dejó por la mañana para volver a la ciudad, donde su padre estaba inquietándose por él» (BD 24). En realidad podríamos decir que la boda para este príncipe es una aventura, tras la cual la princesa se queda sola, casada con un príncipe que, 
de nuevo, la hace esperar y la oculta hasta que sus circunstancias varíen. Ella simplemente acepta la situación.

En los cuentos de Perrault la cualidad indispensable para ser elegida como esposa por el príncipe será la belleza. Las descripciones de las protagonistas femeninas no escapan a los cánones de belleza estereotipados establecidos que arrancan del canon medieval, según el cual ser bella es tener poder sobre el hombre que cae rendido a sus pies, ya que su deseo prevalece sobre su razón (Delumeau 305-345). También encontramos elementos del modelo de belleza renacentista que se mantendría sin alteraciones durante casi 300 años: «Piel blanca, pelo rubio, labios y mejillas rojos, cejas negras. El cuello y las manos debían ser largos y finos; los pies pequeños, la cintura graciosa. Los pechos debían ser firmes, redondos y blancos, con pezones rosados. El color de los ojos podía variar [...], y eventualmente podían hacerse concesiones al pelo oscuro» (Matthews Grieco 79).

En el Renacimiento, siguiendo la línea de pensamiento neoplatónica que establecía la belleza como signo exterior visible de bondad interior invisible, ser bella es un atributo relacionado íntimamente con la moralidad y la posición social. Así, podemos establecer el parámetro bella-buena-noble/aristócrata, en contraposición con la fealdad, que se asociaba a la maldad, al vicio y a la pobreza. Como ejemplo, veamos la descripción de la princesa Piel de asno que luce espléndida sin la piel del animal:

Su rubios cabellos fascinantes / sembrados de diamantes, / cuya luz deslumbrante e irisada / despedía mil rayos, comparables solo a sus ojos admirables, / azules, grandes, dulces y rasgados, / que, de orgullosa majestad cargados, / jamás podrían mirar / sin herir y agradar; / y su cintura, en fin, menuda y fina / que dos manos pudieran abarcar, / mostraron su gentil gracia divina / [...] el buen rey no cabía en sí de gozo / viendo los atractivos de su nuera; / también la reina estaba entusiasmada, / y el príncipe, su amante, sucumbía, / con el alma de júbilo inundada, / al peso de su arrobo y alegría. (PA 257)

Aunque despierta su ardor, su pasión, este príncipe no sucumbe ante su deseo y rechaza la idea de forzar la puerta de la estancia donde ella está, respetándola como reivindican las preciosas. Se retira a palacio y suspira, «llora, hipa, gimotea», actitudes consideradas por el patriarcado más propias de las mujeres que de la masculinidad de un príncipe. «Solo desea un pastel hecho por la mano de Piel de asno»; y la reina madre consiente porque «hay 
que darle gusto y satisfacerle en todo» (PA 251). Los médicos de la corte le diagnostican mal de amores, enfermedad también considerada femenina, y le recomiendan el «himeneo» (el matrimonio) para su cura; él acepta, pero pone como condición que solo lo hará con la que sea dueña del anillo que encontró en el pastel. Este anillo - «estrecho aro de oro» (PA 253)-, que Piel de asno introduce en el pastel, es una variación del zapatito de cristal de Cenicienta y podría representar la vagina, que está íntimamente relacionada con la virginidad, valor deseable en las mujeres. Para Bettelheim:

La sutileza de Perrault queda patente en el detalle de que la zapatilla sea precisamente de cristal, material que no cede, extraordinariamente frágil y que se rompe con facilidad. Un diminuto receptáculo en el que un miembro del cuerpo debe deslizarse e introducirse hasta quedar bien ajustado puede considerarse como un símbolo de la vagina. Algo frágil, que no debe maltratarse porque podría romperse recuerda al himen; algo que se puede perder fácilmente después de una gran fiesta, cuando el amante intenta retener a su pareja, parece una imagen sumamente apropiada para definir la virginidad. [...] Ajustarse la chinela y sobre todo colocarse el otro zapatito, significa aceptar el compromiso del matrimonio y Cenicienta es una novia virgen. (273)

Riquete se enamoró de su princesa por la belleza que mostraba su retrato (RC 123). Esta costumbre medieval se utilizaba en los matrimonios acordados cuando los cónyuges no se conocían y se recoge, por ejemplo, en los Lais de María de Francia y en otros cuentos de hadas, como «La princesa Rosette» de Madame d'Aulnoy. Riquete quiere casarse con esta princesa por su belleza, aunque se la describa como «estúpida» en el cuento (RC 123) (adjetivo que debe entenderse como carente del conocimiento al que aspiraban las preciosas), y le ofrece inteligencia (conocimiento). Este intercambio lo propició el hada que les otorgó los dones al nacer. Riquete tiene como cualidades ser de buena cuna, tener buen carácter, poseer inteligencia (conocimiento) y buenos modales; la belleza que le falta, según vaticinó el hada (RC 129-130), se la otorgará ella si le ama lo suficiente.

En el cuento hallamos otros príncipes que desean casarse con esta princesa; llamó su atención uno "poderoso, rico, inteligente y bien plantado» (RC 126), pero se casó con Riquete. Al final del cuento se recoge que ella hasta lo veía apuesto «con las gafas del amor» (RC 130) y todo termina -según narra el cuento- tal como Riquete había previsto. Este final podría indicar que el

Feminismo/s 35, junio 2020, pp. 235-262 
protagonista masculino cuenta con todas las prerrogativas para alcanzar sus objetivos aunque sea feo y contrahecho, mientras que la princesa tiene que conformarse con responder a las necesidades de Riquete ignorando sus propios deseos. Su voluntad no cuenta, ella solo podrá conseguir lo que Riquete quiera otorgarle. Desde el punto de vista familiar o social, ella no recibe ningún apoyo ni estímulo que la ayude a decidir en libertad.

En «Las hadas» se relata que, además de la belleza, una buena dote es un incentivo para que el príncipe se case con la protagonista, aunque no sea de sangre real: «El hijo del rey que volvía de caza se encontró con ella y, viéndola tan hermosa, le preguntó qué hacía allí sola. [...] Vio salir de su boca cinco o seis perlas y otros tantos diamantes [...] [regalo del hada por ser amable y cortés], se enamoró de ella y, considerando que tal don valía más que todo lo que pudiera aportar al matrimonio, [...] se casó con ella» (H 87-88).

El tema del cuento «Grisélidis» es la paciencia, virtud que deben practicar únicamente las mujeres. El príncipe de este cuento se niega al matrimonio porque tiene una opinión muy negativa de estas. Tras la lectura del texto podemos definirlo como un gran misógino, maltratador psíquico y celoso en extremo. Para él ninguna mujer es digna de ser su esposa porque desconfía de su fidelidad. Considera el matrimonio una atadura necesaria para tener descendencia y piensa que en él siempre debe prevalecer la opinión del marido. El texto es muy claro: se casará si «le encuentran una beldad / joven y sin orgullo y vanidad, / de obediencia acabada, / y de paciencia probada, / y que no tenga propia voluntad» (G 186).

Yendo de caza en el bosque se enamora de una pastora de nombre Grisélidis por su frescura, su aspecto juvenil, recato y discreción, que él considera prueba de un alma pura: «joven tímida, sencilla, dulce y sincera, de piel fresca, ojos azules y boca que conservaba el encanto de la infancia. Cuidaba su rebaño, hilaba, y vivía en su casa del bosque y se hacía su propia ropa» (G 188). Coser e hilar son dos actividades que este príncipe misógino valora, tal vez porque las mujeres las realizan en el ámbito íntimo del hogar.

Su masculinidad, en consonancia con la tradición patriarcal, se pone de manifiesto cuando responde a su Consejo, «voy a tomar esposa / [...] bien nacida, discreta y muy hermosa, / como antaño hicieron mis abuelos» ( $G$ 192). Acuerda el matrimonio con el padre de la pastora y se lo anuncia a esta como un hecho consumado, no sin antes pedirle que le jure que «no tendrá

Feminismo/s 35, junio 2020, pp. 235-262 
jamás ninguna voluntad más que la suya». Ella jura y lo toma por «esposo y señor» (G 196-197).

«Cenicienta» recoge en la escena del baile la prerrogativa del príncipe, del hombre, de elegir esposa entre muchas candidatas; ellas no podrán elegir y tendrán que esperar siempre a ser las elegidas.

\subsection{Los príncipes como esposos}

Salvo «Caperucita roja», los cuentos de Perrault terminan de forma feliz con la boda de ambos protagonistas. Pero no todo es felicidad. Pasados los primeros momentos de la boda y tras el nacimiento de su hija, el príncipe de «Grisélidis» comienza a dudar de su esposa. La espía y, como no consigue pruebas que empañen su virtud, la somete a mil formas de maltrato riguroso: recluirla, desposeerla de su estatus, arrebatarle a su hija, encerrarla en un monasterio, repudiarla y pedirle que instruya a su nueva esposa para que lo complazca, descubriéndole que la elegida es su propia hija. Todo esto para «consolidar sus virtudes innegables» (G 201). El peor aprendizaje que puede generarse de este cuento es que Grisélidis se lo justifica todo porque ella piensa que él busca: «ejercitar mi fe y mi paciencia» (G 202).

Tras la boda, el príncipe de «La bella durmiente» miente y oculta su matrimonio cuando dice a sus padres que «se había perdido cazando en el bosque» (BD 24). Así vivió con la princesa más de dos años y tuvo con ella dos hijos. Solamente hace público su matrimonio cuando es rey, a la muerte de su padre, y marcha a la guerra dejando la regencia a su madre. En la moraleja se da a entender que esperar con paciencia es una virtud que deben poseer las mujeres (BD 29-30), pero el autor nada dice de los hombres.

\subsection{Los príncipes como padres}

El príncipe de «Grisélidis» desea un hijo varón, pero nace una niña que lo conquista por su aire dulce y fascinante y que, sin ningún motivo, él arrebata a su madre. Cuando es adulta, la niña se enamora de un caballero y el padre, que envidia su dicha, traza un pérfido y retorcido plan «para probar el amor de los enamorados» (G 209-220) presentándola a Grisélidis -su madre-como la mujer con la quiere contraer segundas nupcias. El final es feliz, pero el 
modelo de masculinidad y de paternidad que trasmite es nefasto incluso para la época que relata el cuento.

\section{LOS NOBLES: DUEÑOS Y SEÑORES DE SUS ESPOSAS}

Barba azul aparece en el cuento del mismo nombre como un hombre rico. Lo llamaban «Barba azul» por el color de su barba, que causaba el rechazo femenino por el aspecto terrible que le daba. Sus posesiones se describen con detalle en el cuento. Exhibe un modelo de masculinidad que se caracteriza por la fuerza, la violencia, la agresividad, la astucia y el engaño. Se considera dueño de la vida de sus esposas si no cumplen con sus expectativas: «señora, habéis de morir» (BA 54) y propone en el cuento una idea de matrimonio muy particular: «Él le pidió a la madre a una [de sus dos hijas] en matrimonio y dejó a su elección que le diera la que quisiera. [...] las dos eran sumamente hermosas. [...] ya se había casado con varias mujeres y no se sabía nada de ellas» (BA 49). El texto confirma que él quiere una víctima, no una esposa. Invita a su casa a la madre, a las hijas y a sus amigas para impresionarlas con sus riquezas. La que sea su esposa dependerá de él en todos los sentidos (porque no posee conocimientos, ni riqueza, ni tiene una profesión que le dé autonomía) y será envidiada por las demás por su posición en un matrimonio donde él ordena y manda y es dueño incluso de su vida. Por su parte, ella debe obedecer en todo. Esta concepción del matrimonio recuerda a la del príncipe de «Grisélidis».

«Barba azul» incide en las tentaciones sexuales de las mujeres y en la infidelidad que provoca la curiosidad. Para Bettelheim, este cuento gira en torno a dos emociones: una, el amor celoso que está dispuesto a destruir al ser amado para que no lo traicione; y, otra, la fascinación del deseo sexual y el peligro que conlleva caer en él. La infidelidad conyugal representada por la sangre de la llave-que no desaparece- hace que el protagonista masculino castigue a sus esposas con la muerte. La llave, que abre la puerta de la habitación secreta, puede relacionarse con el órgano sexual masculino que desgarra el himen y hace aparecer la sangre -igual que en la llave-, provocando gran angustia a la protagonista, que se estremece al descubrir los cadáveres de las anteriores mujeres asesinadas por cometer esa misma falta (Bettelheim 
309-310). Pero en el cuento no se recoge que exista ningún castigo para las infidelidades masculinas.

Para salvarse, la esposa de Barba azul depende de sus hermanos, que eran dragón y mosquetero respectivamente. Este cuento relata la lucha de hombres contra hombres: por un lado, los hermanos, que se perfilan como «valedores» de las mujeres, capaces de matar por defender a una mujer que es de su familia: «los dos hermanos le persiguieron [...] le traspasaron el cuerpo con la espada y le dejaron muerto» (BA 59); y, por otro, Barba azul, que lucha por lo que considera su propiedad.

En la moraleja, Perrault pretende corregir la curiosidad femenina -considerada un defecto de las mujeres- y sus consecuencias; paradójicamente, la curiosidad asociada con el deseo de saber se entiende como una virtud masculina. La segunda parte de la moraleja dice que la historia que refiere el cuento «es de tiempos remotos, que ya no existen maridos abominables que piden lo imposible; y aunque se sientan insatisfechos o celosos actúan amablemente con sus esposas» (BA 60). Si la protagonista femenina de este cuento fuera respetada en todos los sentidos, como reivindicaban las preciosas, no necesitaría a nadie que la defendiera.

En resumen, el modelo de masculinidad que contiene «Barba azul» es muy negativo porque resalta la importancia que tienen para él el deseo sexual malsano y la posesión de su pareja, aspectos íntimamente relacionados con las emociones violentas y destructivas que no tienen nada que ver con el amor.

El padre de Cenicienta es un gentilhombre viudo que se deja dominar por su nueva esposa y se desentiende de su hija, dejándola a merced de la madrastra, que es orgullosa, altiva y descortés. Esta introduce en el cuento la lucha entre mujeres de la misma generación cuando apoya a sus dos hijas frente a Cenicienta para conseguir que alguna sea elegida por el príncipe, lo que resolvería sus necesidades económicas al beneficiarse de la cercanía al poder masculino. Cabe destacar que en la trama de estos y otros cuentos no aparece la rivalidad entre los hermanos -pero sí aparece entre las hermanas, como podemos ver en este cuento o en «Las hadas»-y los hombres no figuran como padrastros porque no están obligados a proteger a sus hijos para que compitan entre ellos, ya que gozan de autonomía económica por su trabajo o sus riquezas. 


\section{PROTAGONISTAS MASCULINOS DE CLASE SOCIAL BAJA}

Pulgarcito -el menor de siete hermanos- es el protagonista del cuento del mismo nombre. Es pequeño como un pulgar, pero valiente, sagaz, callado, observador y generoso. Su astucia se pone de manifiesto cuando le dice a la ogra que su marido le dijo «que me dieseis todo lo que tiene valor» (P 161). Por sus cualidades hizo fortuna, consiguió ser «correo del rey y con su trabajo compró cargos para que trabajaran su padre y sus hermanos» (P 163), lo mismo que hacían las clases altas cercanas a la corte o la familia de Perrault.

El personaje de Blas, protagonista del cuento «Los deseos ridículos», es leñador de profesión y vive en una choza en el bosque (DR 269). Se queja de que «jamás el cielo empedernido / ningún deseo le había concedido» (DR 268). Desesperado, desea abandonar el monte para descansar y morir. A las quejas de este pobre personaje masculino responde Júpiter, padre de los dioses en la mitología romana, que vive en el cielo y «aparece rayo en mano [...] / pues soy del mundo dueño y soberano» (DR 268), mostrando su gran poder. El leñador intenta que la conversación entre ambos sea de igual a igual, pero Júpiter mantiene la distancia y le concede tres deseos, indicándole que sea prudente en la elección.

Blas está casado con Paquita y, aunque le pide parecer para elegir los deseos, al mismo tiempo sigue la corriente misógina de la época y la insulta, la trata de mala, pécora o charlatana porque no quiere reconocer las consecuencias que ha tenido su descuido al elegir. No en vano, Blas aparece descrito en el cuento como «bebedor de vino, imprudente y torpe» (DR 270). Casi está a punto de pedir como deseo quedarse viudo, ante los improperios de Paquita, cuando desea que una morcilla se pegue a la nariz de ella. Finalmente se impone la cordura y el amor que siente por ella y, despreciando la riqueza, utiliza su tercer deseo para quitarle la morcilla de la nariz y hacer feliz a su esposa. En el cuento no aparece ningún dato de la experiencia amorosa de esta pareja, que no tiene hijos. En la moraleja se incide en que los hombres a la hora de elegir son miserables, ciegos, atolondrados y variables. 


\section{LOS PADRES DE LAS CLASES POBRES COMO PERSONAJES MASCULINOS}

Los padres de las clases pobres que encontramos en estos cuentos siguen la misma línea de actuación que los de las clases nobles, con las diferencias propias de su nivel social y económico. Guillermo -el padre de Pulgarcitoes leñador y tiene siete hijos. Amenaza con pegar a su esposa porque ella le recrimina que consienta perder a sus hijos por no tener con qué alimentarlos. Él toma las decisiones pero no asume sus responsabilidades como padre y «encuentra inoportunas a las mujeres que siempre han tenido razón» (P 145).

El molinero de «El gato con botas» reparte su herencia entre sus tres hijos favoreciendo al mayor. El pequeño solamente heredará el gato, pero conseguirá riqueza y ascenso social gracias a la astucia del animal (GB 67). La figura del padre no aparece en «Caperucita». Está representado simbólicamente por los leñadores que hacen que el lobo posponga sus planes ante su cercanía (Bettelheim 186).

\section{LOS OGROS DE «EL GATO CON BOTAS»Y DE «PULGARCITO»}

El ogro es un «Ser fantástico y gigantesco parecido al hombre que se alimenta de carne humana; persona insociable, cruel o de mal carácter» (DRAE 1469). Pérez-Rioja dice que «en su origen [el ogro] se remonta al mito de Saturno devorador de sus hijos y personifica, simbólicamente, al padre terrible» (322). En «Pulgarcito» el ogro se manifiesta como un ser desconfiado, cruel, violento, que se come a los niños, se erige como rey y señor de su familia y de su mujer - la ogra- a quien manda y ordena como a una sirvienta: «dame rápidamente las botas de siete leguas» (P 159). Por su parte, el ogro de «El gato con botas» aparece como un ser egoísta que vive solo. Su vanidad le pierde cuando, tentado por la astucia del gato, para mostrar su poder se convierte en ratón y este se lo come.

\section{PERSONALES MASCULINOS ANIMALES: EL LOBO DE «CAPERUCITA»Y EL GATO DE «EL GATO CON BOTAS»}

Caperucita roja es la protagonista que da título al cuento. El color rojo simboliza las emociones violentas, sobre todo las de tipo sexual, y la caperuza, su sexualidad incipiente para la que aún no está madura (Bettelheim 181-182). 
En la mitología el lobo se relaciona con la astucia, la crueldad y el mal (Pérez Rioja 274). El protagonista masculino del cuento «Caperucita» es un lobo que planea comérsela. Este lobo no es un animal de presa, sino que encarna, de forma simbólica, a un seductor masculino, egoísta, asocial, activo, atrevido, astuto, listo, tramposo y violento en extremo. Reúne las peores tendencias asociales y primitivas y se guía por sus instintos para destruir a esta niña espontánea, ingenua, tierna, crédula, débil y sin iniciativa.

El lobo vive en el bosque -ámbito externo- y a Caperucita, que vive en su casa con su madre -ámbito interno-, salir para visitar a su abuela enferma le parece algo extraordinario. Cuando el lobo la encuentra en el camino no se la come, sino que la engaña. Escoge el camino más corto para llegar antes a casa de la abuela, la elimina y se hace pasar por ella para poder disponer de la nieta. «Al pasar por el bosque [...] tuvo ganas de comérsela [...] [instintos que reprime] porque andaban por el monte algunos leñadores» ( $C$ 37), que frenan sus planes. En el dualismo propio del cuento, lobo y leñador aparecen como figuras opuestas: el lobo representa la maldad masculina y el leñador simboliza la responsabilidad o el cuidado del padre, la protección y la salvación.

En «Caperucita» se hace hincapié, de forma directa, en la satisfacción sexual masculina: «ven a acostarte conmigo [...], Caperucita se desnudó y se metió en la cama» (C 41). En la moraleja se recoge que el autor identifica a los hombres con los lobos melosos y los considera «peligrosos» (C 42), dando a entender que el objetivo de los hombres es conseguir su satisfacción sexual de cualquier forma o, como el lobo, de forma astuta y complaciente.

El gato era venerado en el antiguo Egipto y considerado en la Edad Media como un animal diabólico. Simboliza la pereza y la lujuria y se le relaciona con lo femenino, la hipocresía, la habilidad y la astucia (Pérez Rioja 221). En «El gato con botas», él es la herencia que le corresponde al hijo pequeño de un molinero que la reparte según el derecho de primogenitura. Este personaje animal con comportamiento masculino es astuto, audaz, estratega, pero a la vez marrullero, pícaro, mentiroso e ingenioso. Con su astucia conseguirá para su amo las posesiones del ogro, ascenso social y el amor de la princesa por los regalos que hace al rey de parte de su amo. 


\section{LA MASCULINIDAD EN LOS CUENTOS DE PERRAULT}

Los personajes masculinos de los cuentos de Perrault transmiten un concepto de masculinidad que concede mayor valor a lo masculino que a lo femenino. Tanto si son protagonistas del cuento como si no lo son, ejercen el poder económico, social, político y cultural sobre los personajes femeninos. Están asociados a cualidades como la fuerza, la inteligencia, la valentía, el conocimiento, la violencia, el poder, la autoridad, el dominio, la agresividad o la necesidad sexual, todos eligen esposas bellas y ellas deben esperar ser las elegidas. Entre ellos se incentiva la competitividad, la demostración de virilidad innecesaria, la búsqueda del riesgo y el uso de la violencia en determinadas circunstancias.

Para satisfacer este modelo de masculinidad las mujeres elegidas deben ser bellas, débiles, torpes, bondadosas, dependientes, pasivas, tiernas, sumisas, pacientes, abnegadas, volubles y grandes sufridoras, complacer y solventar las necesidades del marido y atender al hogar y a los hijos. Una buena dote es otra razón de peso para ser elegida como esposa. Aunque cumplan con todos los requisitos exigidos, los personajes masculinos tienen un concepto negativo de las mujeres -sexo débil o bello sexo, según convenga-, considerándolas vanidosas, perezosas, falsas, perversas, torpes, astutas, curiosas o coquetas. Pueden disponer de ellas a su antojo porque se consideran sus dueños y señores -incluso de su vida, como hemos visto en «Barba azul»-, y así deben ellas aceptarlo.

Algunos se resisten al matrimonio, o lo aceptan como obligación para dar a la corona un heredero que perpetúe su linaje, considerando que pierden su libertad al casarse. Paradójicamente, las mujeres no pierden nada cuando se casan: ellas ganan el espacio privado del hogar porque ese es el destino para el que se han preparado desde pequeñas.

Los personajes masculinos valoran en ellas la fidelidad y la virginidad y satisfacen sus necesidades sexuales dentro del matrimonio, ya que van encauzadas a la procreación. Si nace una niña, aunque le corresponda por linaje, no reinará: se mantendrá en el hogar cuidando de su familia y necesitará un consorte masculino para hacerlo rey. En los cuentos se habla de matrimonio, de pasión, de conquista y de boda, terminando con el «Y vivieron felices...» como fórmula de cierre, pero los protagonistas masculinos no expresan 
sentimientos de amor verdadero. Confunden amor con deseo, posesión o conquista, sufren celos patológicos y son grandes misóginos, como hemos visto en «Grisélidis» o en «Barba azul». En «Piel de asno» el incesto entre padre e hija -que no se da entre madre e hijo- se justifica moral, política y socialmente y se resuelve bien gracias a la ayuda del hada.

Los protagonistas masculinos aparecen como héroes, con profesión definida y con el campo de acción siempre fuera del hogar. Ejercen de padres distantes socialmente aceptados, reconocidos y bien valorados, capaces de tomar decisiones, que las protagonistas femeninas siempre deberán acatar. Nunca aparecen realizando tareas domésticas ni compartiendo la crianza de la prole con sus esposas.

El concepto de masculinidad hegemónica, asociada a los valores del patriarcado, que impera en estos cuentos, contribuye a perpetuar e institucionalizar las estructuras de dominación y las desigualdades de género, reproduciendo siempre los mismos roles y manteniendo de forma continuada un discurso homogeneizante que no tiene en cuenta a las mujeres como sujetos históricos, niega su diversidad y sus vivencias propias y no plantea otras alternativas. El patriarcado alienta desde dentro, porque lo ayuda a mantenerse, la competencia entre las mujeres para conseguir al príncipe. Esta competencia las desune y provoca envidia y falta de solidaridad ente ellas porque solo una será la elegida. El resultado será la subordinación constante de la mujer al hombre, basándose siempre en parámetros de obediencia y dominación. A cambio, si cumplen con lo establecido, ellas obtienen -como en el cuento- el premio del matrimonio y un final «feliz», que consiste en vivir por y para el hombre el resto de su vida, ofreciendo una imagen inamovible de sí mismas que lleva implícita la falta de autoestima, el convencimiento de no sentirse completas por no tener pareja o por no tener hijos y la dependencia emocional, parámetros sobre los que se construyen las relaciones malsanas o el maltrato.

\section{CONCLUSIONES}

Aunque los cuentos de Perrault son un acierto de recopilación y de creación, los arquetipos masculinos que encontramos en ellos y el concepto de masculinidad que transmiten no responden al concepto de masculinidad 
que necesitamos en la actualidad. El aprendizaje que estos cuentos generan, desde la infancia, perpetúa un concepto de masculinidad patriarcal que se retroalimenta de la información del cuento y ayuda a sostener las desigualdades entre hombres y mujeres presentes en nuestra sociedad. No queremos decir que no se lean o no se cuenten los cuentos de Perrault, pero sí que, al menos, se explique que contienen un perfil de masculinidad que responde a otra época y se establezca, de forma clara, la diferencia entre el concepto de masculinidad que manifiestan y el que se necesita en la actualidad para conseguir una correcta socialización de género.

La cultura de la desigualdad está íntimamente relacionada con el control que se ejerce sobre el otro, por lo que podemos utilizar el cuento como herramienta de socialización que, desde la infancia, contribuya a eliminar las inequidades que se establecen a partir de la diferenciación en base al sexo o al género. Podemos introducir en los contenidos de los cuentos, en sus imágenes o en la forma de contarlos otros arquetipos que apoyen nuevas masculinidades carentes de sesgos que respondan a nuestra realidad social, para que en ella se favorezca el intercambio de roles buscando la conciliación del mundo laboral, de la vida personal y familiar, de forma que hombres y mujeres se impliquen por igual.

Es importante revindicar la expresión de los afectos y las emociones masculinas para mejorar las relaciones de hombres y mujeres en su vida cotidiana, así como incluir nuevos conceptos sobre el amor, el matrimonio, la confianza o la autoestima. Buscaremos siempre deslegitimar la violencia como norma general, en particular la física, la sexual o la psicológica y utilizar como método de resolución de conflictos el dialogo pacífico y la negociación.

Para ello debemos repensar los modelos de masculinidad que aprendemos a partir de los cuentos a fin de contribuir a desaprender este modelo de masculinidad que conocemos y aprendemos desde la infancia y contar o leer cuentos que presenten otras alternativas. Para conseguirlo proponemos deconstruir los cuentos de Perrault o escribir otros nuevos que generen nuevas masculinidades, de forma que los hombres hagan suyas las reivindicaciones femeninas y reafirmen su compromiso con un nuevo concepto de masculinidad donde la igualdad, el respeto y la inclusión sean una realidad. 


\section{REFERENCIAS BIBLIOGRÁFICAS}

Anderson, Bonnie S., y Judith P. Zinsser. Historia de las mujeres: una historia propia. 2 vols. Barcelona: Crítica, 1992.

Beauvoir, Simone. El segundo sexo. Buenos Aires: Siglo veinte, 1981.

Bettelheim, Bruno. Psicoanálisis de los cuentos de hadas. Barcelona: Crítica, 1999.

Bonino Méndez, Luis. «Masculinidad hegemónica e identidad masculina». Dossiers feministes 6 (2002): 7-35.

Bourdieu, Pierre. La dominación masculina. Barcelona: Anagrama, 2000.

Connell, Robert W. «La organización social de la masculinidad». Ediciones de las Mujeres 24 (1997): 31-48.

Defrance, Anne. «De la caverne matricielle au tombeau: L'Ile de la Félicité de Madame d'Aulnoy, premier conte de fées littéraire français». Cahiers du C.R.L.H. 11 (1997): 145-152.

Delumeau, Jean. «Les agents de Satan. III : La femme». La peur en Occident. XIV au XVIII ${ }^{e}$ siècle. París: Fayard, 1978. 305-345.

Denis, Delphine. «'Sçavoir la carte': voyage au Royaume de la Galanterie». Études littéraires 34. 1-2. (2002): 179-191.

Dens, Jean-Pierre. «Honnête homme et esthétique du paraître». Papers on French Seventeenth Century Literature 6 (1976-1977): 69-82.

Dulong, Claude. «De la conversación a la creación». Historia de las mujeres: del Renacimiento a la Edad Moderna. Dras. Arlette Fargue y Natalie Zemon Davis.

T. 3. Madrid: Taurus, 1992. 425-451.

D’Urfé, Honoré. L'Astrée. París: Gallimard, 1996.

Fairclough, Norman. «El análisis crítico del discurso como método de investigación en ciencias sociales». Método de análisis crítico del discurso. Comps. Ruth Wodak y Michael Meyer. Barcelona: Gedisa, 2003. 179-201.

Faret, Nicolas. L'honnête homme ou L'art de plaire à la cour. Ed. M. Magendie. Ginebra: Slatkine, 1970.

Fernández Rodríguez, Carolina. La bella durmiente a través de la historia. Oviedo: Universidad de Oviedo, 1998.

Garrido Carrasco, Vicenta. Mujeres y hadas: desde el cuento a las reivindicaciones femeninas. Jaén: Universidad de Jaén, 2015.

Henriot, Émile. «De qui sont les Contes de Perrault?». Revue des Deux Mondes. 43 (15 de enero de 1928): 424-441.

Jociles Rubio, María José. «El estudio sobre las Masculinidades: panorámica general». Gaceta de Antropología 17 (2001). 1 de julio de 2019. Granada: 
Universidad de Granada <http://www.ugr.es/ pwlac/G17_27MariaIsabel_ Jociles_Rubio.html>

La Fayette, Madame de (Marie-Madeleine Pioche de La Vergne, comtesse de). La Princesse de Clèves. París: Flammarion, 2008.

L'Héritier de Villandon, Marie-Jeanne. OEuvres mêlées. París: Jean Guignard, 1696.

19 de marzo de 2018. Gallica <http://gallica.bnf.fr/ark:/12148/bpt6k62376r> Matthews Grieco, Sara F. «El cuerpo, apariencia y sexualidad». Historia de las mujeres en occidente. Dras. Arlette Fargue y Natalie Zemon Davis. T. 3. Madrid: Taurus, 1992. 68-109.

Mongrédien, Georges. Les précieux et les précieuses. París: Mercure de France, 1939.

Pérez Rioja, José Antonio. Diccionario de símbolos y mitos. Madrid: Tecnos, 1971.

Perrault, Charles. Cuentos de antaño. [Histoires, ou Contes du temps passé, avec des moralités, Grisélidis, nouvelle, avec le conte de Peau d'asne, et celuy des Souhaits ridicules] Il. Gustavo Doré. Trad. pról. y not. J. Evheramonno y E. Pascual. 3. ${ }^{a}$ ed. Madrid: Gaviota, 1996.

Prado Biezma, Javier del. «El feminismo ambiguo de Molière». Thélème: Revista Complutense de Estudios Franceses 23 (2008): 123-147.

Propp, Vladimir. Las raíces históricas del cuento. Madrid: Fundamentos, 1998.

Real Academia Española. Diccionario de la lengua española. Vigésimo segunda ed. 2 vols. Madrid: Real Academia Española, 1992.

Sau Sánchez, Victoria, y María Jayme. Psicología diferencial del sexo y el género. Barcelona: Icaria, 2004.

Soriano, Marc. Los cuentos de Perrault. Buenos Aires: Siglo XXI Argentina Editores, 1975.

Van Dijk, Teun A. Texto y contexto. Madrid: Catedra, 1993.

Yllera Fernández, Alicia. «El siglo XVII». Historia de la literatura francesa. Coord. Javier del Prado. Madrid: Cátedra, 1994. 421-422. 